Article

\title{
Czochralski Growth, Magnetic Properties and Faraday Characteristics of $\mathrm{CeAlO}_{3}$ Crystals
}

\author{
Feiyun Guo, Qiyuan Li, Huaimin Zhang, Xiongsheng Yang, Zhen Tao, Xin Chen and \\ Jianzhong Chen * \\ College of Chemistry, Fuzhou University, Fuzhou 350116, China; fyguo@fzu.edu.cn (F.G.); \\ n161320205@fzu.edu.cn (Q.L.); n161320181@fzu.edu.cn (H.Z.); n181320206@fzu.edu.cn (X.Y.); \\ n171320197@fzu.edu.cn (Z.T.); xin.chen@fzu.edu.cn (X.C.) \\ * Correspondence: j.z.chen@fzu.edu.cn
}

Received: 3 April 2019; Accepted: 8 May 2019; Published: 11 May 2019

\begin{abstract}
CeAlO}_{3}$ crystals were grown in different growth atmospheres by the Czochralski method. The lattice parameters and space group of $\mathrm{CeAlO}_{3}$ crystal were determined by Rietveld structure refinement of X-ray diffraction (XRD) data. The influence of $\mathrm{Ce}^{4+}$ ions in the crystal on the transmittance and crystal color was confirmed by XPS analysis. Magnetization curve at room temperature and temperature dependencies of the magnetic susceptibility in two different directions were measured, indicating that $\mathrm{CeAlO}_{3}$ crystal has remarkable magnetic anisotropy and there is an abnormal magnetic behavior in the vertical $<001>$ direction in the temperature range of 50-150 K. Faraday characteristics of $\mathrm{CeAlO}_{3}$ crystal were investigated at room temperature. Verdet constants of $\mathrm{CeAlO}_{3}$ at 532, 635 and $1064 \mathrm{~nm}$ are about 2.1 times as large as those of $\mathrm{CeF}_{3}$. The reason of large Verdet constants was analyzed based on the Van Vleck-Hebb theory and the magnetic circular dichroism (MCD) spectrum.
\end{abstract}

Keywords: Czochralski method; lattice parameters; magnetic properties; Faraday rotation

\section{Introduction}

Faraday isolators are important components currently used for high-power-laser machinery and advanced optical communications, guaranteeing a unidirectional light propagation in the laser systems [1,2]. Due to recent development in laser applications such as precise measurements and advanced display systems, the demand for optical Faraday devices using wavelengths of 400-1100 nm is increasing, where ferrimagnetic yttrium iron garnets (YIG) and doped YIG are inapplicable because of their poor transparency. Paramagnetic magneto-optical materials containing rare earth ions (such as $\mathrm{Tb}^{3+}, \mathrm{Eu}^{2+}$ and $\mathrm{Ce}^{3+}$ ) are suitable for use in this band, although their Verdet constants are smaller than those of doped YIG. As is known, crystals [3-6], glasses [7-9] and ceramics [10,11] containing $\mathrm{Tb}^{3+}$ ions have been extensively investigated as Faraday rotator materials due to its good magneto-optic effect in the visible and near-infrared bands and relatively easy preparation process. However, at the present, the crystals containing $\mathrm{Ce}^{3+}$ ions have drawn people's attention [12-15]. Compared to $\mathrm{Tb}^{3+}$ ions, $\mathrm{Ce}^{3+}$ ions have larger electron effective transition wavelengths and higher transition efficiency, and $\mathrm{CeO}_{2}$ raw material is relatively cheap.

Rare earth aluminate $\left(\mathrm{REAlO}_{3}\right)$ crystallizes in a perovskite-type structure. It has a high content of rare earth ions per-unit volume, which is advantageous for enhancing the magneto-optical effect of the crystal. $\mathrm{TbAlO}_{3}$ crystal belongs to an orthorhombic system with two optical axes, although exhibiting good magneto-optical properties [16], it is difficult to apply to Faraday devices in the 400-1100 nm band due to its low symmetry. Different from $\mathrm{TbAlO}_{3}, \mathrm{CeAlO}_{3}$ shows a tetragonal symmetry with a space group of $\mathrm{P} 4 / \mathrm{mmm}$ or $\mathrm{I} / \mathrm{mcm}$ at room temperature [17-20]. In this series of rare earth aluminate, $\mathrm{CeAlO}_{3}$ is an unusual one, undergoing three phase transitions above room 
temperature [21]. In the past three decades, the crystal structure and phase transition of $\mathrm{CeAlO}_{3}$ compounds have been extensively studied and confirmed. Its magnetic and electrical properties have also been reported [22,23], but little research has been done on the growth and properties of bulk crystals. Until 2015, $\mathrm{CeAlO}_{3}$ crystals with large sizes were obtained first time through the Edge-defined Film Fed Growth (EFG) techniques by Arhipov et al. [24]. The optical, luminescence and magnetic properties of $\mathrm{CeAlO}_{3}$ were studied. They also tried to grow the $\mathrm{CeAlO}_{3}$ crystals by varying different growth parameters using the Czochralski method, but did not obtain cylindrically shaped crystals.

To our knowledge, there are few reports on the magneto-optical properties of Ce-containing crystals. In this paper, Czochralski growth, magnetic properties and magneto-optical characteristics of $\mathrm{CeAlO}_{3}$ crystals are investigated.

\section{Experimental Procedure}

The polycrystalline materials for crystal growth were prepared by solid-state reaction according to the following chemical reaction equation:

$$
\mathrm{CeO}_{2}+0.5 \mathrm{Al}_{2} \mathrm{O}_{3} \rightarrow \mathrm{CeAlO}_{3}+0.25 \mathrm{O}_{2} \uparrow
$$

Stoichiometric amounts of $\mathrm{CeO}_{2}(4 \mathrm{~N})$ and $\mathrm{Al}_{2} \mathrm{O}_{3}(4 \mathrm{~N})$ were weighed accurately, then the mixture was sintered at three different temperatures $\left(1350,1450\right.$ and $\left.1500{ }^{\circ} \mathrm{C}\right)$ for 12 to $20 \mathrm{~h}$ in the flowing $5 \% \mathrm{H}_{2}+95 \% \mathrm{Ar}$ atmosphere each with intermediate grinding and pressing into tablets. Sintering needed to be performed multiple times until the strongest diffraction peak of $\mathrm{CeO}_{2}$ near 28.5 degrees in the X-ray diffraction (XRD) patterns disappeared substantially. $\mathrm{CeAlO}_{3}$ crystals were grown by the Czochralski method, in a $\Phi 60 \mathrm{~mm} \times 38 \mathrm{~mm}$ iridium crucible with radio frequency (RF) induction heating. It was found when pure Ar was used as protection atmosphere in the growth process, $\mathrm{CeAlO}_{3}$ crystal obtained presented a flat shape and dark green color, as shown in Figure 1a. Parameters such as growth rate and rotation speed were adjusted, and the crystal shape did not change significantly. Finally, when $5 \% \mathrm{H}_{2}+95 \% \mathrm{Ar}$ was used as growth atmosphere, the $\mathrm{CeAlO}_{3}$ crystal obtained was cylindrical and the green color was obviously lighter, as shown in Figure 1b. A portion of the greenish $\mathrm{CeAlO}_{3}$ crystal was cut out and annealed under the following conditions: a flowing $5 \% \mathrm{H}_{2}+95 \% \mathrm{Ar}$ atmosphere, and a constant temperature of $1550{ }^{\circ} \mathrm{C}$ for $30 \mathrm{~h}$. The annealed $\mathrm{CeAlO}_{3}$ sample presents a light yellow color, as shown in Figure 1c.

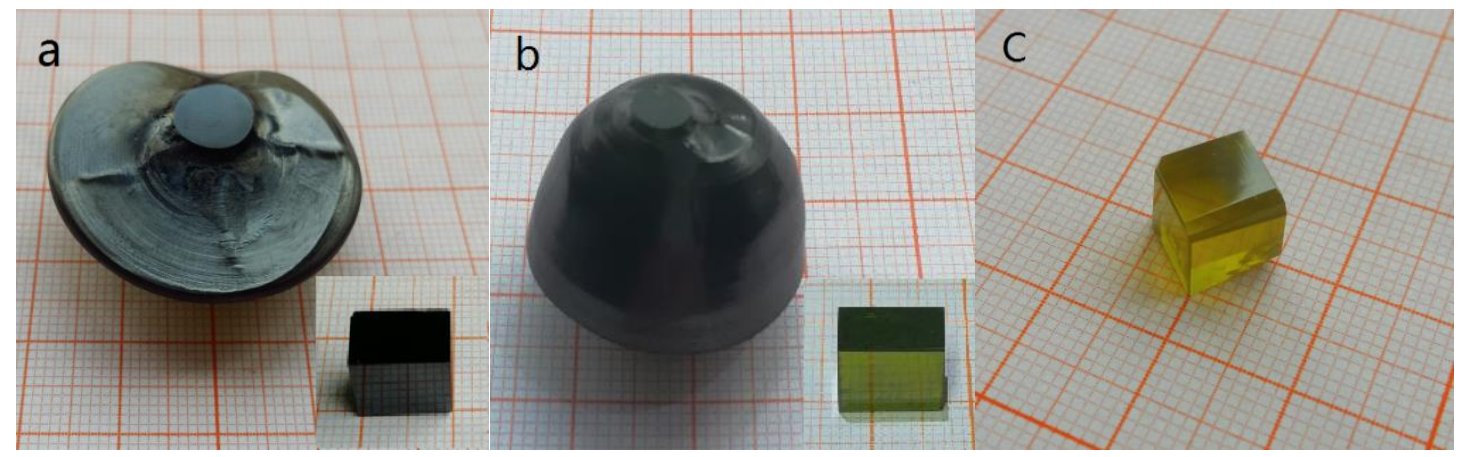

Figure 1. Photographs of as-grown $\mathrm{CeAlO}_{3}$ crystals: (a) grown at pure Ar atmosphere, (b) grown at $5 \%$ $\mathrm{H}_{2}+95 \%$ Ar atmosphere, (c) annealed sample.

X-ray powder diffraction was performed by a computer automatic diffractometer (Rigaku Ultima IV, Rigaku, Tokoy, Japan ) using Cu-K $\alpha$ radiation $(\lambda=1.54056 \AA)$ in the range $10^{\circ} \leq 2 \theta \leq 80^{\circ}$ with a scanning step of $0.01^{\circ}$ and a scanning rate of $0.15^{\circ} / \mathrm{min}$. The annealed and unannealed greenish $\mathrm{CeAlO}_{3}$ crystals were cut along (001) plane, which were oriented by X-ray diffraction, and then grounded and polished carefully to $1.0 \mathrm{~mm}$ thickness for spectra and XPS measurement. Transmission spectra were measured over the wavelength range 250-2500 nm (Lambda 900, Perkin-Elmer, Waltham, MA, 
USA). Ce valance band spectra of two samples were recorded by XPS ( ESCALAB 250XI, ThermoFisher, Waltham, MA, USA). The oriented $\mathrm{CeAlO}_{3}$ sample with sizes $3.5 \mathrm{~mm} \times 3.5 \mathrm{~mm} \times 3.5 \mathrm{~mm}$ was used for magnetic susceptibility testing (JDAW-2000D vibrating sample magnetometer, YINGPU MAGNETIC, Changchun, China) and DC magnetization measurements (PPMS6000, Quantum Design, San Diego, CA, USA). Faraday rotation of annealed $\mathrm{CeAlO}_{3}$ crystal at 532, 635 and $1064 \mathrm{~nm}$ were measured by the extinction method, and a commercial $\mathrm{CeF}_{3}$ crystal (Beijing Scitlion Technology Corp., LTD, Beijing, China) was as a comparison during the test process. The magnetic field could be adjusted from 0 to $1.2 \mathrm{~T}$ continuously. Magnetic circular dichroism (MCD) spectra of annealed crystal samples with $0.2 \mathrm{~mm}$ thickness were measured by using a circular dichroism spectrometer (MOS-450, Bio-Logic, Auvergne-Rhône-Alpes, France) equipped with a magnetic field equipment of 2500 Oe intensity (the magnetic field paralleled to the propagation direction of probe light). All measurements were performed at room temperature.

\section{Results and Discussion}

\subsection{Crystal Growth}

$\mathrm{CeAlO}_{3}$ is congruent compound with a melting point of about $2348 \mathrm{~K}$ [25], it could be grown by the Czochralski method. It is difficult to obtain $\mathrm{CeAlO}_{3}$ crystals with high optical quality due to the high melting point and oxidation of $\mathrm{Ce}^{3+}$. When pure Ar was used as the growth atmosphere, A small amount of $\mathrm{Ce}^{3+}$ oxidation may be present in the melt, $\mathrm{CeAlO}_{3}$ crystallized from the melt is dark in color and strongly absorbs thermal radiation, resulting in a decrease in temperature gradient between the melt and crystal, making crystal growth in the length direction becomes difficult. The longitudinal temperature gradient can be increased by the crucible position adjustment and the thickness decrease of the insulation layer of the post-heat chamber, but the surface temperature of Ir crucible may exceed $2600 \mathrm{~K}$, and Ir has a risk of melting (2727K). Arhipov et al. [24] used a tungsten crucible as growth container through $\mathrm{CZ}$ method, as-grown $\mathrm{CeAlO}_{3}$ crystal also showed a flat shape. When the weakly reducing atmosphere, $5 \% \mathrm{H}_{2}+95 \% \mathrm{Ar}$, was used, it can inhibit the oxidation of $\mathrm{Ce}^{3+}$ in the melt, resulting in the crystallized $\mathrm{CeAlO}_{3}$ crystal becoming lighter in color, reducing the absorption of thermal radiation, and finally obtaining a cylindrical $\mathrm{CeAlO}_{3}$ crystal with diameter $20 \mathrm{~mm}$ and length $22 \mathrm{~mm}$.

\subsection{Structure Determination}

Tas and Akinc [26], and Shishido et al. [17,18] reported the structure of $\mathrm{CeAlO}_{3}$ at room temperature with space group P4/mmm and the primitive tetragonal cell $\mathrm{a}=3.7669(9) \AA$ and $\mathrm{c}=3.7967(7) \AA$. In 2004, Fu et al. reinvestigated the room temperature structure of $\mathrm{CeAlO}_{3}$ through Rietveld refinement, and revealed a super cell $\mathrm{a}=5.32489(6) \AA$ and $\mathrm{c}=7.58976(10) \AA$, with the space group I4/mcm [19]. In order to verify the rationality of these two space groups, powder X-ray diffraction data of $\mathrm{CeAlO}_{3}$ crystal was used for Rietveld refinement according to the above two space group models, the refined results are listed in Tables 1 and 2. Indeed, there were only small differences between the two agreement factors, but the refined thermal parameters based on the $\mathrm{P} 4 / \mathrm{mmm}$ model were larger than those of based on $\mathrm{I} / \mathrm{mcm}$, particularly, the thermal anisotropy between basal oxygen atoms which can be found in Table 1. So, $\mathrm{I} 4 / \mathrm{mcm}$ is considered to be a more reasonable space group for $\mathrm{CeAlO}_{3}$, the refined cell parameters are $\mathrm{a}=5.32064(12) \AA, \mathrm{c}=7.5810$ (3) $\AA$. Figure 2 shows the observed, calculated and differences between $\mathrm{X}$-ray diffraction profiles of the as-grown $\mathrm{CeAlO}_{3}$ crystal. 
Table 1. Refined structural parameters for the as-grown $\mathrm{CeAlO}_{3}$ crystal according to the $\mathrm{P} 4 / \mathrm{mmm}$ model.

\begin{tabular}{cccccc}
\hline Atoms & Site & $\mathbf{x}$ & $\mathbf{y}$ & $\mathbf{z}$ & $\mathbf{B}\left(\AA^{\mathbf{2}}\right)$ \\
\hline $\mathrm{Ce}$ & $1 \mathrm{~d}$ & 0.5 & 0.5 & 0.5 & $0.0087(4)$ \\
$\mathrm{Al}$ & $1 \mathrm{a}$ & 0 & 0 & 0 & $0.0232(12)$ \\
$\mathrm{O}(1)$ & $2 \mathrm{f}$ & 0.5 & 0 & 0 & $0.056(5)$ \\
$\mathrm{O}(2)$ & $2 \mathrm{f}$ & 0 & 0.5 & 0 & $0.01(2)$ \\
$\mathrm{O}(3)$ & $1 \mathrm{~b}$ & 0 & 0 & 0.5 & $0.000(3)$ \\
\hline
\end{tabular}

Weighted profile R-factor Rwp $=9.78 \%$ and Profile residual $\mathrm{Rp}=7.35 \%$ with the Goodness-of-fit of 1.76 .

Table 2. Refined structural parameters for the as-grown $\mathrm{CeAlO}_{3}$ crystal according to $\mathrm{I} / \mathrm{mcm}$ model.

\begin{tabular}{cccccc}
\hline Atoms & Site & $\mathbf{x}$ & $\mathbf{y}$ & $\mathbf{z}$ & $\mathbf{B}\left(\AA^{2}\right)$ \\
\hline $\mathrm{Ce}$ & $4 \mathrm{~b}$ & 0.5 & 0 & 0.25 & $0.0055(6)$ \\
$\mathrm{Al}$ & $4 \mathrm{c}$ & 0 & 0 & 0 & $0.0076(15)$ \\
$\mathrm{O}(1)$ & $4 \mathrm{a}$ & 0 & 0 & 0.25 & $0.005(4)$ \\
$\mathrm{O}(2)$ & $8 \mathrm{~h}$ & $0.2812(11)$ & $0.7812(11)$ & 0 & $0.005(3)$
\end{tabular}

Weighted profile R-factor Rwp $=8.64 \%$ and Profile residual $\mathrm{Rp}=8.22 \%$ with the Goodness-of-fit of 1.79 .

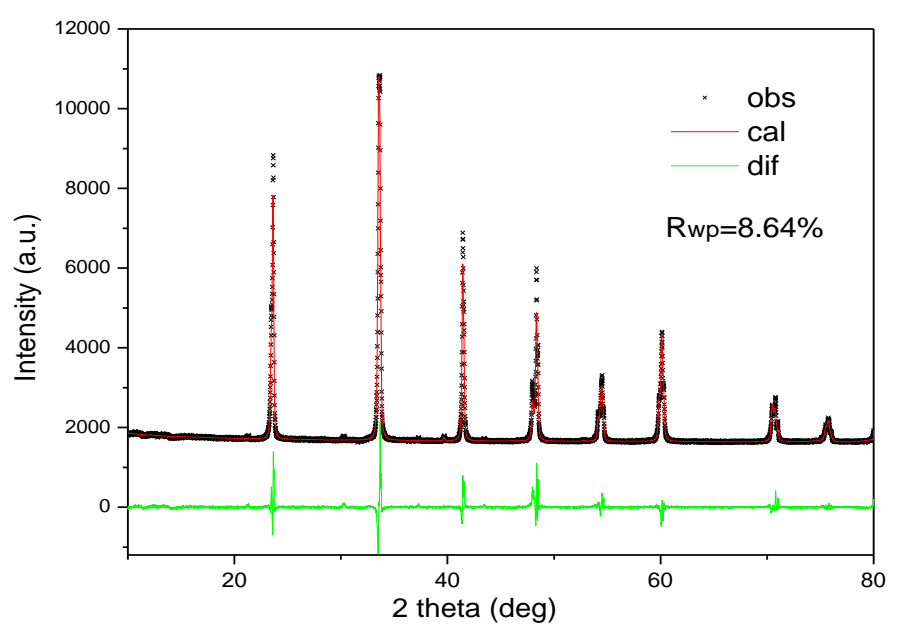

Figure 2. X-ray diffraction (XRD) patterns of the as-grown $\mathrm{CeAlO}_{3}$ crystal.

\subsection{Transmission Spectra and Ce Valence State Analysis}

Figure 3 shows the transmission spectra of different growth atmosphere and annealed $\mathrm{CeAlO}_{3}$ samples at 250-2500 nm waveband. The transmittance of $\mathrm{CeAlO}_{3}$ grown in $\mathrm{Ar}$ was relatively low, which corresponds to the dark color presented by the crystal. Although the transmittance of $\mathrm{CeAlO}_{3}$ grown in 5\% $\mathrm{H}_{2}+95 \%$ Ar was improved, there was still a large absorption in the 500-1500 $\mathrm{nm}$ band. After annealing at $1550{ }^{\circ} \mathrm{C}$ for $30 \mathrm{~h}$ in a flowing $5 \% \mathrm{H}_{2}+95 \% \mathrm{Ar}$, the transmittance of $\mathrm{CeAlO}_{3}$ crystal increased obviously, up to $68 \%$ or higher at $550-2500 \mathrm{~nm}$ regions and the short wavelength edge of optical absorption was shifted to $\sim 380 \mathrm{~nm}$. In order to verify that the above transmittance and corresponding crystal color change were related to the presence of $\mathrm{Ce}^{4+}$ ions, the valence state of Ce ions in the crystal was analyzed. Figure 4; Figure 5 show the Ce3d XPS spectra collected from greenish and yellowish $\mathrm{CeAlO}_{3}$ samples, respectively. Both XPS spectra have four peaks at almost the same position, located at $882.1 \pm 0.1 \mathrm{eV}, 886.0 \pm 0.1 \mathrm{eV}, 900.3 \pm 0.1 \mathrm{eV}$ and $904.4 \pm 0.1 \mathrm{eV}$. The peaks at $882.1 \pm 0.1 \mathrm{eV}$ and $886.0 \pm 0.1 \mathrm{eV}$ correspond to the pairs of $\mathrm{Ce} 3 \mathrm{~d} 5 / 2$ spin-orbit doublets, while peaks at $900.3 \pm 0.1 \mathrm{eV}$ and $904.4 \pm 0.1 \mathrm{eV}$ correspond to the pairs of Ce $3 \mathrm{~d} 3 / 2$ spin-orbit doublets. The band energies of spin-orbit splitting between $3 \mathrm{~d} 5 / 2$ and $3 \mathrm{~d} 3 / 2$ are about $18.3 \mathrm{eV}$, in agreement with that of $\mathrm{CePO}_{4}$ [27]. However, due to the overlap of the photo-electron peaks of $\mathrm{Ce}(\mathrm{III})$ and $\mathrm{Ce}(\mathrm{IV})$, these four peaks cannot be used to identify the valence state of the Ce ions. It is believed that the peak near $917 \mathrm{eV}$ is the fingerprint of the $\mathrm{Ce}(\mathrm{IV})$ compound [28]. The small peak observed at $916.7 \mathrm{eV}$ in Figure 4 
confirms the presence of $\mathrm{Ce}^{4+}$ ions in the greenish $\mathrm{CeAlO}_{3}$ crystal, and estimates that its percentage ratio does not exceed $1 \%$. However, no $\mathrm{Ce}^{4+}$ ion was found in the yellowish $\mathrm{CeAlO}_{3}$ crystal within the error of XPS measurement.

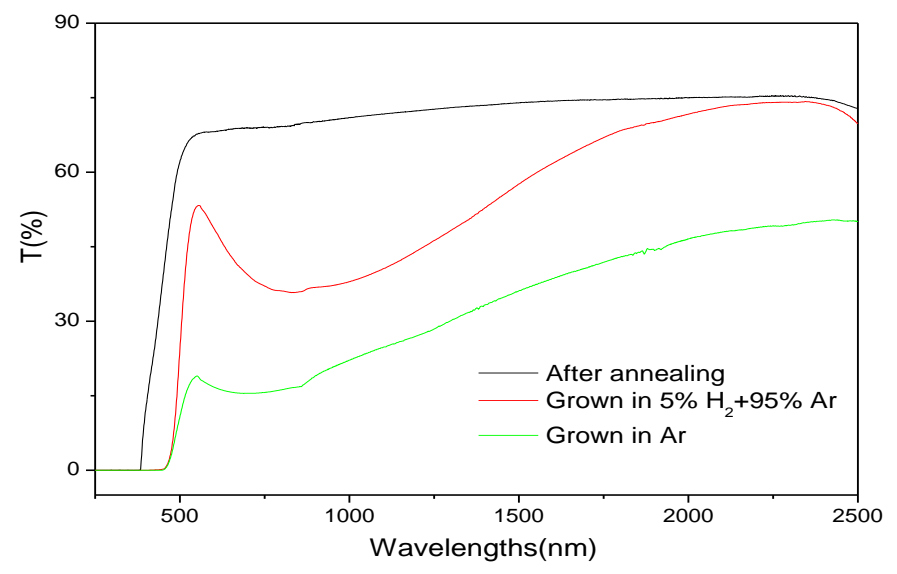

Figure 3. Transmittance of $\mathrm{CeAlO}_{3}$ crystals annealed and grown in different growth atmospheres.

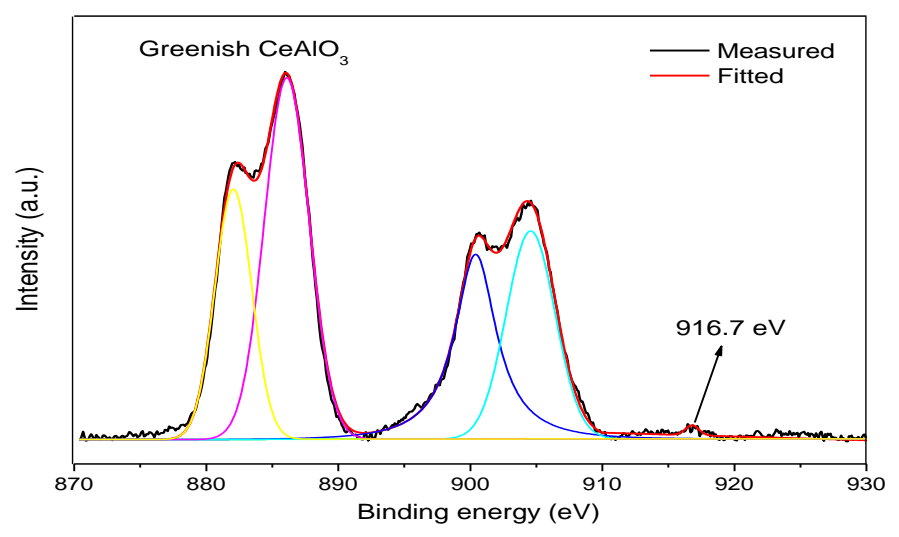

Figure 4. $\mathrm{Ce} 3 \mathrm{~d}$ XPS spectrum of the greenish $\mathrm{CeAlO}_{3}$ crystal sample.

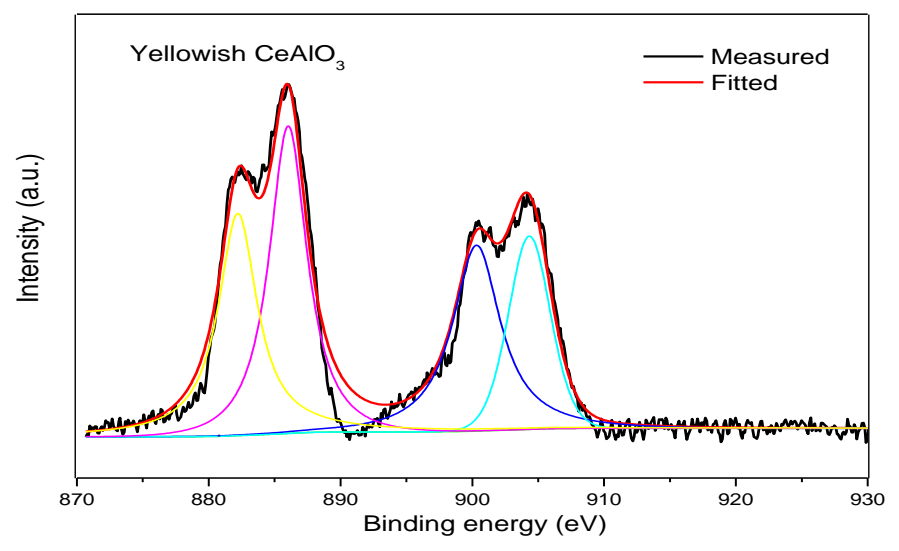

Figure 5. Ce3d XPS spectrum of the yellowish $\mathrm{CeAlO}_{3}$ crystal sample.

\subsection{Magnetic Analysis}

As shown in Figure 6, the magnetization curve displays that $\mathrm{CeAlO}_{3}$ is a paramagnetic compound, which is magnetically anisotropic. The calculated mass magnetic susceptibility at room temperature in the vertical and parallel $<001>$ directions are $1.04 \times 10^{-7} \mathrm{~m}^{3} / \mathrm{Kg}$ and $1.78 \times 10^{-7} \mathrm{~m}^{3} / \mathrm{Kg}$, respectively. The degree of anisotropy increases by a factor of approximately six upon cooling from room temperature to $2 \mathrm{~K}$. The magnetic behavior of paramagnetic lanthanide compounds was mainly influenced by 
dipole-dipole interactions and crystal-field (CF) effects, whereas super-exchange interactions were relatively unimportant. The influence of dipole-dipole interactions can be described by the Curie-Weiss law [29]. Temperature dependencies of the inverse magnetic susceptibility $\chi^{-1}$ of $\mathrm{CeAlO}_{3}$ crystal in the vertical and parallel $<001>$ directions are shown in Figure 7 . The curve of $\chi^{-1}$ vs $T$ in the parallel $<001>$ direction shows a good linear trend over the 4-300 K range, fitted data based on the Curie-Weiss law gives an effective moment of $2.57 \mu_{\mathrm{b}}$, is consistent with the theoretical value $2.54 \mu_{\mathrm{b}}$ for the free ion ${ }^{2} \mathrm{~F}_{5 / 2}$ ground state of $\mathrm{Ce}^{3+}$. The corresponding Curie-Weiss temperature is approximately $-2.34 \mathrm{~K}$, which is different from the result of polycrystalline or unoriented single $\mathrm{CeAlO}_{3}$ crystals reported by other authors [22,24]. But in the vertical $<001>$ direction, the relationship between $\chi^{-1}$ and $\mathrm{T}$ at 50-150 K range does not obey the Curie-Weiss law. In light of the interpretation of magnetic properties of oriented $\mathrm{CeF}_{3}$ single crystals [30], this anomalous behavior of the magnetic susceptibility could be explained in the crystal-field model with $\mathrm{Ce}^{3+}$ ion energy levels based on the $\mathrm{D}_{2 \mathrm{~d}}$ site symmetry. It is noted that abrupt magnetic changes in both directions of the $\mathrm{CeAlO}_{3}$ crystal near $4 \mathrm{~K}$ were observed, which indicates the transition of the $\mathrm{CeAlO}_{3}$ crystal from a paramagnetic phase to an antiferromagnetic one. This magnetic phase transition was also found in $\mathrm{TbAlO}_{3}$ and $\mathrm{DyAlO}_{3}$. Most analyses assume that the ordering of magnetic sublattices at low temperature is due to a combination of exchange and dipole interactions [31].

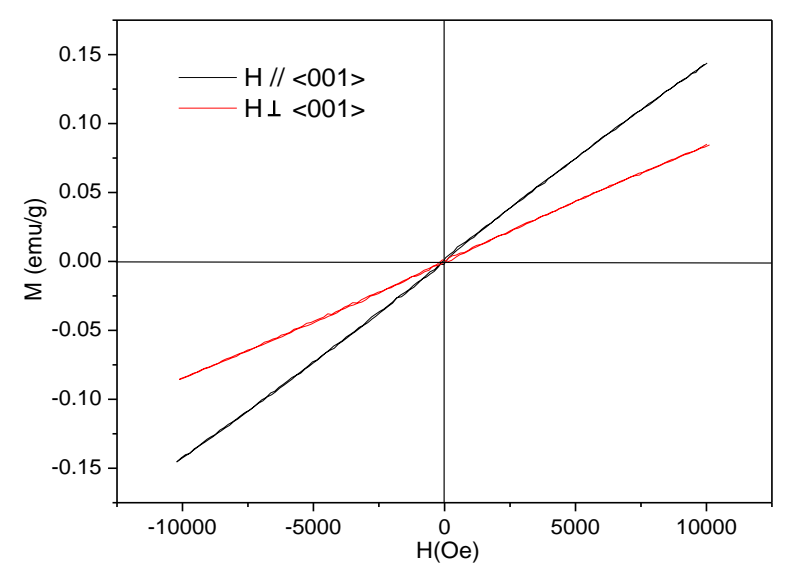

Figure 6. Magnetization curve of $\mathrm{CeAlO}_{3}$ crystal at different directions.

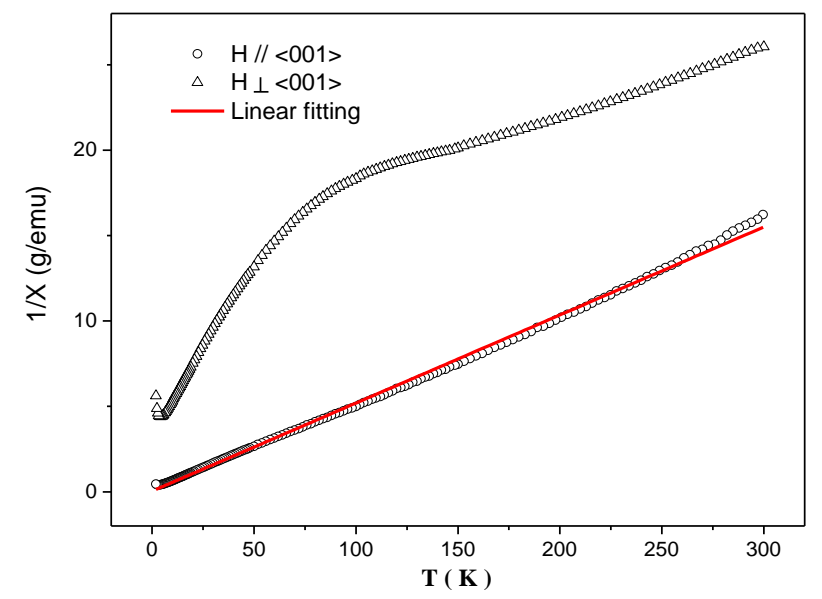

Figure 7. Temperature dependencies of the inverse magnetic susceptibility of $\mathrm{CeAlO}_{3}$ crystal at different directions.

\subsection{Faraday Rotation}

It is well known that Faraday rotation in a paramagnetic material is proportional to the applied magnetic field, the length of light-passing medium and the Verdet constant, which is itself a function 
of the wavelength. Faraday rotations of $\mathrm{CeAlO}_{3}$ and $\mathrm{CeF}_{3}$ crystals vs the magnetic field in the range of 0-1.2 $\mathrm{T}$ are linear at three wavelengths, as shown in Figure 8. The Verdet constants of the two crystals can be calculated from the slope of lines, which are $-389 \mathrm{rad} / \mathrm{m} \cdot \mathrm{T}$ at $532 \mathrm{~nm},-270 \mathrm{rad} / \mathrm{m} \cdot \mathrm{T}$ at $635 \mathrm{~nm}$ and $-79.7 \mathrm{rad} / \mathrm{m} \cdot \mathrm{T}$ at $1064 \mathrm{~nm}$ for $\mathrm{CeAlO}_{3},-180 \mathrm{rad} / \mathrm{m} \cdot \mathrm{T}$ at $532 \mathrm{~nm},-125 \mathrm{rad} / \mathrm{m} \cdot \mathrm{T}$ at $635 \mathrm{~nm}$ and $-39.1 \mathrm{rad} / \mathrm{m} \cdot \mathrm{T}$ at $1064 \mathrm{~nm}$ for $\mathrm{CeF}_{3}$, respectively. Compared with $\mathrm{CeF}_{3}$ and TGG, Verdet constants of $\mathrm{CeAlO}_{3}$ at the corresponding wavelengths are about 2.1 times those of $\mathrm{CeF}_{3}$ and about two times those of TGG reported [32].

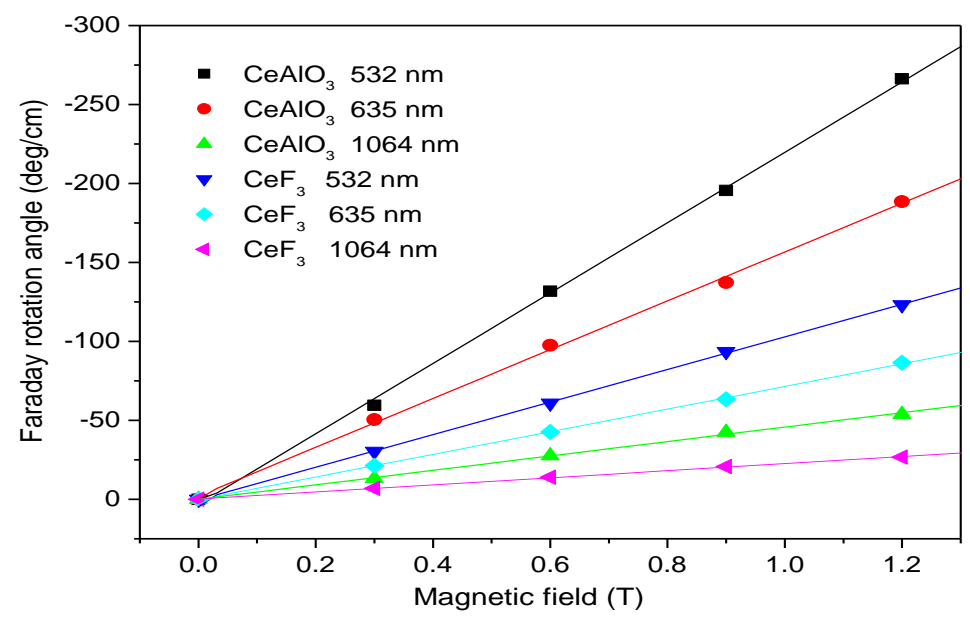

Figure 8. Relationships between the Faraday rotation and magnetic field of $\mathrm{CeAlO}_{3}$ and $\mathrm{CeF}_{3}$ crystals at different wavelengths.

As for paramagnetic materials of glass or crystal, when the interaction between rare earth ions is small, based on the Van Vleck-Hebb theory with a single-oscillator model, the relationship between Verdet constants $V$ and wavelength $\lambda$ is used as the following equation [33-35]:

$$
V^{-1}=\frac{g \mu_{B} c h}{4 \pi^{2} n \chi C_{t}}\left(1-\frac{\lambda^{2}}{\lambda_{t}^{2}}\right)
$$

where $\mathrm{g}$ is the Landé factor, $\mu_{B}$ the Bohr magneton, $c$ the velocity of light, $h$ the Planck constant, $n$ the refraction index (it can be estimated by the transmittance of crystal [4]), $\chi$ the volume magnetic susceptibility and $C_{t}$ the transition probability. The terms $n, \chi$ and $C_{t}$ are functions of temperature, and when the temperature is constant, could be considered as a constant, so the inverse of Verdet constant is in linear relationship with proportional to the wavelength square. Fitting the wavelength-dependence data for two crystals to Equation (2) yields the effective transition wavelength $\lambda_{t}$ and probability $C_{t}$ at room temperature, listed in Table 3 together with $n$ and $\chi$ for comparison. According to Equation (2) and Table $3, \mathrm{CeAlO}_{3}$ has larger Verdet constants than those of $\mathrm{CeF}_{3}$ owing to its large refraction index, volume magnetic susceptibility and effective transition wavelength, although the $4 \mathrm{f}$ to $4 \mathrm{f} 5 \mathrm{~d}$ transition efficiency of $\mathrm{Ce}^{3+}$ in the $\mathrm{CeAlO}_{3}$ perovskite is relatively small. Substituting the above calculated parameters into Equation (2), the relationships between Verdet constants and the wavelength of $\mathrm{CeAlO}_{3}$ and $\mathrm{CeF}_{3}$ were plotted, as shown in Figure 9.

Table 3. The fitting and calculated parameters of two crystals at room temperature according to Equation (2). (The refraction index and volume magnetic susceptibilities are also listed).

\begin{tabular}{ccccc}
\hline \multicolumn{1}{c}{ Prystals } & $\boldsymbol{n}(\mathbf{a t} \mathbf{1 0 6 4} \mathbf{n m})$ & $\chi\left(\mathbf{e m u} / \mathbf{c m}^{\mathbf{3}} \cdot \mathbf{T}\right)$ & $\lambda_{t}(\mathbf{n m})$ & $\boldsymbol{C}_{\boldsymbol{t}}\left(\mathbf{1 0} \mathbf{- 4 5} \mathbf{J} \cdot \mathbf{c m}^{\mathbf{3}}\right)$ \\
\hline $\mathrm{CeAlO}_{3}$ & 2.08 & 0.942 & 280 & 22.0 \\
$\mathrm{CeF}_{3}$ & 1.64 & 0.686 & 239 & 26.2 \\
\hline
\end{tabular}




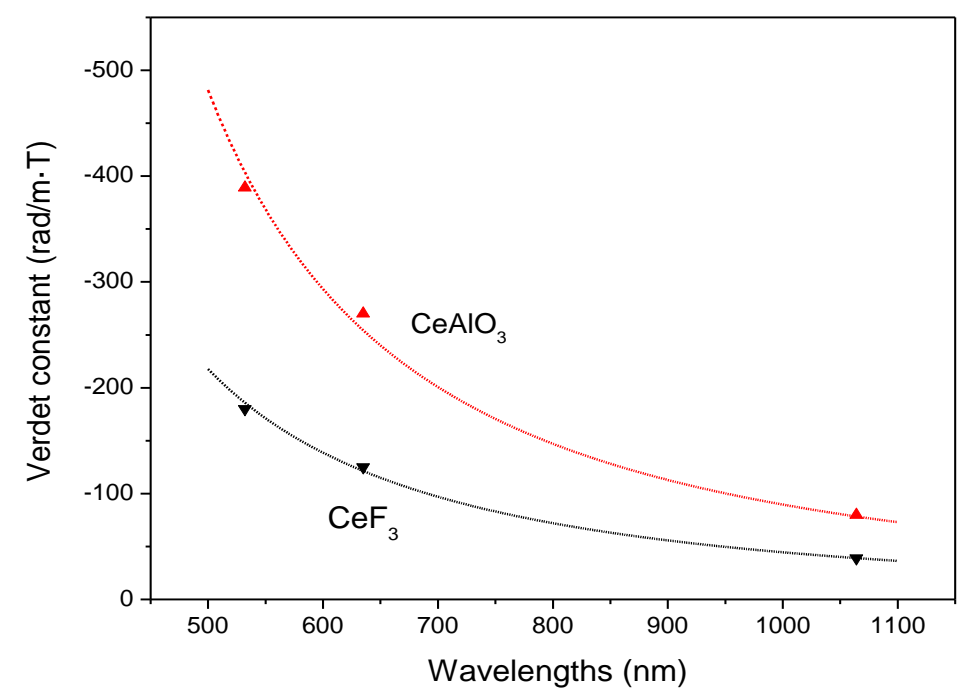

Figure 9. Verdet constant as a function of the wavelength for $\mathrm{CeAlO}_{3}$ and $\mathrm{CeF}_{3}$ crystals.

\subsection{Magnetic Circular Dichroism}

Faraday magneto-optical effect of rare earth ions is mainly caused by the transitions of $4 \mathrm{f}-4 \mathrm{f5} \mathrm{d}[36,37]$, which is essentially the circular birefringence induced by the applied magnetic field. MCD signal of the rare earth magnetic ions at the transition absorption can be indicative of their magneto-optical activity (MOA) [38]. Usually the shorter the transition absorption wavelength and the stronger the intensity, the stronger the corresponding MCD signal. Figure 10 shows the MCD spectra of $\mathrm{CeAlO}_{3}$ and $\mathrm{CeF}_{3}$ crystals at 2500 Oe magnetic fields. At the 350-800 nm waveband, MCD spectrum of $\mathrm{CeAlO}_{3}$ shows two peaks centred at $366.3 \mathrm{~nm}$ and $372.7 \mathrm{~nm}$, respectively, which can correspond to the $4 \mathrm{f}-5 \mathrm{~d}$ transition of $\mathrm{Ce}^{3+}$ ions in the perovskite. Below $350 \mathrm{~nm}$, no MCD signal can be detected because of the absorption of right-handed and left-handed light by $\mathrm{CeAlO}_{3}$ sample exceeds the detection range of the instrument. Reducing the thickness of sample may detect the MCD signal below $350 \mathrm{~nm}$, but it is difficult to process the $\mathrm{CeAlO}_{3}$ sample. Due to the strong influence of the surrounding coordination ions and the weak crystal-field interaction, the $4 \mathrm{f}-5 \mathrm{~d}$ transition absorption position of $\mathrm{Ce}^{3+}$ ions in the $\mathrm{CeF}_{3}$ matrix is below $300 \mathrm{~nm}$, so only a $\mathrm{MCD}$ signal of $\mathrm{CeF}_{3}$ peaked at $271.3 \mathrm{~nm}$ can be found at the $200-800 \mathrm{~nm}$ waveband. The peak intensity is much smaller than that of $\mathrm{CeAlO}_{3}$ at $366.3 \mathrm{~nm}$ and $372.7 \mathrm{~nm}$, indicating the relatively weak $\mathrm{MOA}$ of $\mathrm{Ce}^{3+}$ ions in the $\mathrm{CeF}_{3}$ matrix.

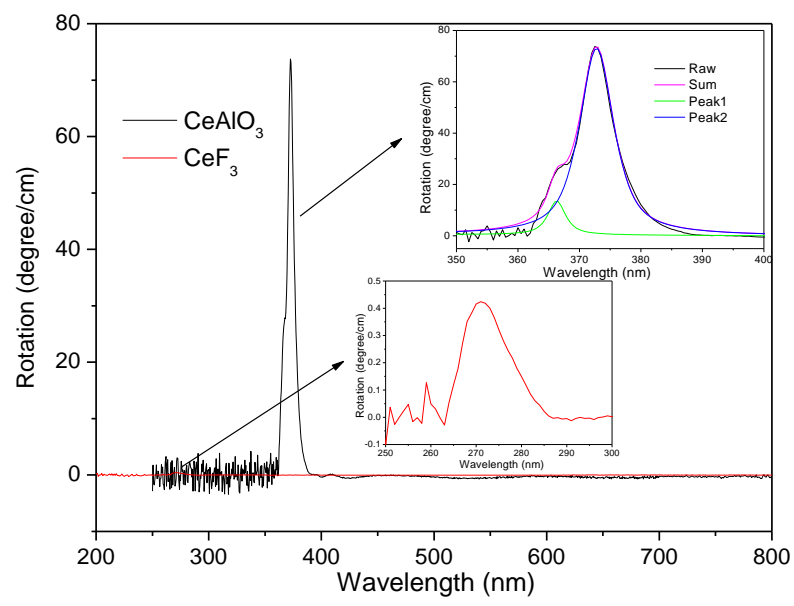

Figure 10. Magnetic circular dichroism (MCD) spectra of $\mathrm{CeAlO}_{3}$ and $\mathrm{CeF}_{3}$ crystals, Inset: Peak position of $\mathrm{CeAlO}_{3}$ and $\mathrm{CeF}_{3}$ crystals. 


\section{Conclusions}

The $\mathrm{CeAlO}_{3}$ crystal with a diameter of $20 \mathrm{~mm}$ and a length of $22 \mathrm{~mm}$ has been grown in $5 \% \mathrm{H}_{2}+$ 95\% atmosphere by the Czochralski method. Rietveld structure refinement of XRD data confirms that the $\mathrm{CeAlO}_{3}$ crystallizes in the tetragonal system at room temperature, space group I4/ $\mathrm{mcm}$. The green color and corresponding optical absorption exhibited by as-grown $\mathrm{CeAlO}_{3}$ crystal are related to the presence of $\mathrm{Ce}^{4+}$ ions according to the XPS analysis. Secondary annealing of optimized conditions can greatly reduce the content of $\mathrm{Ce}^{4+}$ in $\mathrm{CeAlO}_{3}$ crystal and improve the transmittance. Above $4 \mathrm{~K}$, $\mathrm{CeAlO}_{3}$ crystal exhibits paramagnetism and magnetic anisotropy. There is an anomalous behavior of the magnetic susceptibility in the vertical $<001>$ direction over $50-150 \mathrm{~K}$ range, which can be explained in the crystal-field model. The present investigations demonstrate $\mathrm{CeAlO}_{3}$ crystal have larger Verdet constants than those of $\mathrm{CeF}_{3}$ and TGG at 532, 635 and $1064 \mathrm{~nm}$ wavelengths at room temperature. So $\mathrm{CeAlO}_{3}$ crystal maybe a candidate magneto-optical material for Faraday devices in the visible and near-infrared regions. Based on the analysis of Van Vleck-Hebb theory, the co-contribution of the large refraction index, volume magnetic susceptibility and effective transition wavelength is the reason why $\mathrm{CeAlO}_{3}$ have large Verdet constants, which will help to find other new magneto-optical crystals containing $\mathrm{Ce}^{3+}$ applied in the visible and near-infrared regions.

Author Contributions: F.G. and J.C. conceived and designed the experiments; Q.L., H.Z., X.Y., Z.T. and X.C. performed the experiments and analyzed the data; F.G. wrote the paper; J.C. modified the article.

Funding: This research was funded by National Natural Science Foundation of China, grant number 61775039 and 51602054 .

Conflicts of Interest: The authors declare no conflict of interest.

\section{References}

1. Khazanov, E.A. Investigation of Faraday isolator and Faraday mirror designs for multi-kilowatt power lasers. Proc. SPIE 2003, 4968, 115-126.

2. Zheleznov, D.; Starobor, A.; Palashov, O.; Chen, C.; Zhou, S. High-power Faraday isolators based on TAG ceramics. Opt. Express. 2014, 22, 2578-2583. [CrossRef]

3. Shimamura, K.; Kito, T.; Castel, E.; Latynina, A.; Molina, P.; Víllora, E.G.; Mythili, P.; Veber, P.; Chaminade, J.-P.; Funaki, A.; et al. Growth of $\left\{\mathrm{Tb}_{3}\left[\mathrm{Sc}_{2}-\mathrm{xLu}\right]\left(\mathrm{Al}_{3}\right) \mathrm{O}_{12}\right.$ single crystals for visible-infrared optical isolators. Cryst. Growth Des. 2010, 10, 3466-3470. [CrossRef]

4. Guo, F.; Sun, Y.; Yang, X.; Chen, X.; Zhao, B.; Zhuang, N.; Chen, J. Growth, Faraday and inverse Faraday characteristics of $\mathrm{Tb}_{2} \mathrm{Ti}_{2} \mathrm{O}_{7}$ crystal. Opt. Express. 2016, 24, 5734-5743. [CrossRef]

5. Jin, W.Z.; Ding, J.X.; Guo, L.; Gu, Q.; Li, C.; Su, L.B.; Wu, A.H.; Zeng, F.M. Growth and performance research of $\mathrm{Tb}_{3} \mathrm{Ga}_{5} \mathrm{O}_{12}$ magneto-optical crystal. J. Cryst. Growth. 2018, 484, 17-20. [CrossRef]

6. Man, P.; Ma, F.; Xie, T.; Ding, J.; Wu, A.; Su, L.; Li, H.; Ren, G. Magneto-optical property of terbiumlutetium-aluminum garnet crystals. Opt. Mater. 2017, 66, 207-210. [CrossRef]

7. Tanaka, K.; Hirao, K.; Soga, N. Large Verdet constant of $30 \mathrm{~Tb}_{2} \mathrm{O}_{3} \cdot 70 \mathrm{~B}_{2} \mathrm{O}_{3}$ glass. Jpn. J. Appl. Phys. 1995, 34, 4825-4826. [CrossRef]

8. Gao, G.; Winterstein-Beckmann, A.; Surzhenko, O.; Dubs, C.; Dellith, J.; Schmidt, M.A.; Wondraczek, L. Faraday rotation and photoluminescence in heavily $\mathrm{Tb}^{3+}$-doped $\mathrm{GeO}_{2}-\mathrm{B}_{2} \mathrm{O}_{3}-\mathrm{Al}_{2} \mathrm{O}_{3}-\mathrm{Ga}_{2} \mathrm{O}_{3}$ glasses for fiber-integrated magneto-optics. Sci. Rep. 2015, 5, 8942. [CrossRef]

9. Ding, J.; Man, P.; Chen, Q.; Guo, L.; Hu, X.; Xiao, Y.; Su, L.; Wu, A.; Zhou, Y.; Zeng, F. Influence of Tb ${ }^{3+}$ concentration on the optical properties and verdet constant of magneto-optic ABS-PZZ glass. Opt. Mater. 2017, 69, 202-206. [CrossRef]

10. Zheleznov, D.; Starobor, A.; Palashov, O.; Lin, H.; Zhou, S. Improving characteristics of faraday isolators based on TAG ceramics by cerium doping. Opt. Lett. 2014, 39, 2183. [CrossRef]

11. Snetkov, I.L.; Permin, D.A.; Balabanov, S.S.; Palashov, O.V. Wavelength dependence of Verdet constant of $\mathrm{Tb}^{3+}: \mathrm{Y}_{2} \mathrm{O}_{3}$ ceramics. Appl. Phys. Lett. 2016, 108, 740. [CrossRef]

12. Molina, P.; Vasyliev, V.; Víllora, E.G.; Shimamura, K. $\mathrm{CeF}_{3}$ and $\mathrm{PrF}_{3}$ as uv-visible Faraday rotators. Opt. Express. 2011, 19, 11786-11791. [CrossRef] [PubMed] 
13. Víllora, E.G.; Shimamura, K.; Plaza, G.R. Ultraviolet-visible optical isolators based on $\mathrm{CeF}_{3}$ Faraday rotator. J. Appl. Phys. 2015, 117, 233101. [CrossRef]

14. Starobor, A.; Mironov, E.; Snetkov, I.; Palashov, O.; Furuse, H.; Tokita, S.; Yasuhara, R. Cryogenically cooled $\mathrm{CeF}_{3}$ crystal as media for high-power magneto-optical devices. Opt. Lett. 2017, 42, 1864. [CrossRef]

15. Guo, F.Y.; Gui, X.P.; Tao, Z.; Sun, Y.L.; Chen, X.; Chen, J.Z. Growth, magnetic anisotropy and Faraday characteristics of $\mathrm{NaCe}\left(\mathrm{MoO}_{4}\right)_{2}$ crystal. Opt. Mater. 2018, 84, 658-662. [CrossRef]

16. Uygun, V.V.; Abdulla, A.U.; Sharof, A.R.; John, B.G.; Kelly, L.N.; Dhiraj, K.S.; Gary, W.B. Faraday effect and magnetic susceptibility analyses in $\mathrm{TbAlO}_{3}$. J. Appl. Phys. 2008, 104, 073903.

17. Shishido, T.; Nojima, S.; Tanaka, M.; Horiuchi, H.; Fukuda, T. Flux growth of perovskite-type $\mathrm{RA} \mathrm{O}_{3}$ single crystals. J. Alloys Compd. 1995, 227, 175-179. [CrossRef]

18. Shishido, T.; Zheng, Y.T.; Saito, A.; Horiuchi, H.; Kudou, K.; Okada, S.; Fukuda, T. Microstructure, thermal properties and hardness of the $\mathrm{CeMO}_{3}(\mathrm{M}=\mathrm{A} 1, \mathrm{Ga})$ synthesized by arc-melting method. J. Alloys Compd. 1997, 260, 88-92. [CrossRef]

19. Fu, W.T.; IJdo, D.J.W. The structure of $\mathrm{CeAlO}_{3}$ by Rietveld refinement of X-ray powder diffraction data. J. Solid State Chem. 2004, 177, 2973-2976. [CrossRef]

20. Vasylechko, L.; Senyshyn, A.; Trots, D.; Niewa, R.; Schnelle, W.; Knapp, M. CeAlO 3 and $\mathrm{Ce}_{1-x} \mathrm{R}_{\mathrm{x}} \mathrm{AlO}_{3}(\mathrm{R}=\mathrm{La}$, $\mathrm{Nd}$ ) solid solutions: Crystal structure, thermal expansion and phase transitions. J. Solid State Chem. 2007, 180, 1277-1290. [CrossRef]

21. Fu, W.T.; IJdo, D.J.W. “Unusual” phase transitions in $\mathrm{CeAlO}_{3}$. J. Solid State Chem. 2006, 179, $2732-2738$. [CrossRef]

22. Shishido, T.; Iwasaki, H.; Toyota, N. Magnetic properties of $\mathrm{CeAlO}_{3}$. J. Alloys Compd. 1994, 209, L11-L13. [CrossRef]

23. Shelykh, A.I.; Melekh, B.T. $\mathrm{CeAlO}_{3}$ Crystals: Preparation and Study of Their Electrical and Optical Characteristics. Phys. Solid State. 2003, 45, 248-252. [CrossRef]

24. Arhipov, P.; Tkachenko, S.; Gerasymov, I.; Sidletskiy, O.; Hubenko, K.; Vasyukov, S.; Shiran, N.; Baumer, V.; Mateychenko, P.; Fedorchenko, A.; et al. Growth and characterization of large $\mathrm{CeAlO}_{3}$ perovskite crystals. J. Cryst. Growth. 2015, 430, 116-121. [CrossRef]

25. Mizuno, M.; Berjoan, R.; Coutures, J.; Foex, M. High Temperature Phase Studies on the System $\mathrm{Al}_{2} \mathrm{O}_{3}-\mathrm{Ln}_{2} \mathrm{O}_{3}$ with a Solar Furnace. In Proceedings of the International Solar Energy Society Congress, Los Angeles, CA, USA, 28 July-1 August 1975.

26. Tas, A.C.; Akinc, M. Phase relations in the system $\mathrm{Ce}_{2} \mathrm{O}_{3}-\mathrm{Al}_{2} \mathrm{O}_{3}$ in inert and reducing atmospheres. J. Am. Ceram. Soc. 1994, 77, 2961-2967. [CrossRef]

27. Beché, E.; Charvin, P.; Perarnau, D.; Abanades, S.; Flamant, G. Ce3d XPS investigation of cerium oxides and mixed cerium oxide $\left(\mathrm{Ce}_{\mathrm{x}} \mathrm{Ti}_{\mathrm{y}} \mathrm{O}_{\mathrm{z}}\right)$. Surf. Interface. Anal. 2010, 40, 264-267. [CrossRef]

28. Mullins, D.R.; Huntley, D.R.; Overbury, S.H. Electron spectroscopy of single crystal and polycrystalline cerium oxide surfaces. Surf. Sci. 1998, 409, 307-319. [CrossRef]

29. Galyametdinov, Y.; Athanassopoulou, M.A.; Griesar, K.; Kharitonova, O.; Soto Bustamante, E.A.; Tinchurina, L.; Ovchinnikov, I.; Haase, W. Synthesis and magnetic investigations on rare-earth-containing liquid crystals with large magnetic anisotropy. Chem. Mat. 1996, 8, 922-926. [CrossRef]

30. Savinkov, A.V.; Korableva, S.L.; Tagirov, M.S.; Suzuki, H.; Matsumoto, K.; Abe, S. Revised Measurements and Interpretation of Magnetic Properties of Oriented $\mathrm{CeF}_{3}$ Single Crystals. J. Low Temp. Phys. 2016, 185, 603-608. [CrossRef]

31. Cashion, J.D.; Wells, M.R. Magnetic interactions in $\mathrm{DyA}_{1} \mathrm{O}_{3}$ and $\mathrm{TbA}_{1} \mathrm{O}_{3}$. J. Magn. Magn. Mater. 1998, 177-181, 781-782. [CrossRef]

32. Raja, M.Y.A.; Allen, D.; Sisk, W. Room-temperature inverse Faraday effect in terbium gallium garnet. Appl. Phys. Lett. 1995, 67, 2123-2125. [CrossRef]

33. Van Vleck, J.H.; Hebb, M.H. On the paramagnetic rotation of tysonite. Phys. Rev. 1934, 46, 17-32. [CrossRef]

34. Akamatsu, H.; Fujita, K.; Nakatsuka, Y.; Murai, S.; Tanaka, K. Magneto-optical properties of Eu ${ }^{2+}$-containing aluminoborosilicate glasses with ferromagnetic interactions. Opt. Mater. 2013, 35, 1997-2000. [CrossRef]

35. Malakhovskii, A.V.; Edelman, I.S.; Sukhachev, A.L.; Markov, V.V.; Voronov, V.N. Magneto-optical activity of f-f transitions in elpasolite $\mathrm{Rb}_{2} \mathrm{NaDyF}_{6}$. Opt. Mater. 2009, 32, 243-246. [CrossRef]

36. Xu, Y.; Duan, M. Theory of Faraday rotation and susceptibility of rare-earth trifluorides. Phys. Rev. B 1992, 46, 11636. [CrossRef] 
37. Duan, M.Q.; Xu, Y. A theoretical investigation on the magneto-optical effect of $\mathrm{CeF}_{3}$ and $\mathrm{NdF}_{3}$. J. Magn. Magn. Mater. 1992, 115, 1-8. [CrossRef]

38. Klochkov, A.A.; Valiev, U.V.; Moskvin, A.S. The role of $4 \mathrm{f}-4 \mathrm{f}$ transitions in magnetooptics of paramagnetic rare-earth glasses. Phys. Status Solidi B 1991, 167, 337-348. [CrossRef]

(C) 2019 by the authors. Licensee MDPI, Basel, Switzerland. This article is an open access article distributed under the terms and conditions of the Creative Commons Attribution (CC BY) license (http://creativecommons.org/licenses/by/4.0/). 